\title{
EVALUATION OF SOLAR ENERGY POTENTIAL AND PV MODULE PERFORMANCE IN THE GOBI DESERT OF MONGOLIA
}

\author{
Amarbayar Adiyabat ${ }^{1}$, Kosuke Kurokawa ${ }^{1}$, Kenji Otani $^{2}$, N.Enebish ${ }^{3}$, \\ G.Batsukh $^{3}$, M.Battushig ${ }^{3}$, D.Ochirvaani ${ }^{3}$, B.Ganbat ${ }^{3}$
}

1. Tokyo University of Agriculture and Technology (TUAT), Naka-cho 2-24-16, Koganei, Tokyo 184-8588, Japan, Tel: +81-423-88-7445 Fax: +81-42-388-7445

2. National Institute of Advanced Industrial Science \& Technology, Tsukuba Central 2, Tsukuba, Ibaraki, 305-8568, Japan, Tel: +81-298-615152, Fax: +81-298-615829

3. Inter-University Solar Energy Research Net-Center, National Univ. of Mongolia, P.O.Box 46A/436, Ulaanbaatar, 210546, Mongolia

\section{ABSTRACT}

This paper presents the evaluation results of solar energy potential and photovoltaic module performance from measured data at the test site in the Gobi Desert of Mongolia

For the purpose to estimate solar energy potentials and durability of PV systems in the Gobi desert area, a data acquisition system, which includes 75W, 80W modules and two set of precision pyranometers, thermometers and anemometers has been installed at the Sainshand city in October, 2002. The system allows measuring 23 parameters including solar irradiation and meteorological parameters for every 10 minutes.

It has been observed that the high output gain due to the operating condition in an extreme low ambient temperature and the module performance ratio indicated very high value ( 0.9 or more) in the winter. The monthly variation of in-plane irradiation and PV module output shows relatively small range in a year due to low ambient temperature and the precipitation that concentrated on the summer time.

\section{KEYWORDS}

Solar Energy Resource - 1: PV Module Performance - 2:

\section{INTRODUCTION}

It is expected that Gobi Desert, Mongolia is one of most promising candidate site for introducing of 100MW class Very Large Scale Photovoltaic Systems (VLS-PV) specified by the IEA PVPS Task 8 "Very Large Scale Photovoltaic power generation Systems" programme. Within framework of the feasibility study conducted by Task 8 activity it has been developed a conceptual design and done the trial calculation of the power generation cost and the construction cost for VLS-PV system in Gobi Desert area case ${ }^{[2]}$. However, it is considered that the meteorological environment characteristics of Gobi desert might affect to the PV system performance and design specifications.

In order to verify PV module performance in Gobi desert area condition it has been installed two types of the crystalline silicon PV modules and checking devices (e.g. I-V curve tracer, etc.) as well as a new data acquisition system and meteorological devices to study the characteristics of the photovoltaic system operation in the severe natural environment at the test site in Gobi 
desert area of Mongolia. The purpose of this study is to study the output simulation technique for the VLS-PV to confirm the efficiency of using the large scale PV system to be installed in the Desert area, and also to clarify the specification requirement for the VLS-PV system design.

\section{EXPERIMENTAL SETUP}

In order to determine the potential of VLS-PV in Gobi desert area it has been installed two types of the crystalline silicon PV modules and checking devices (e.g. I-V curve tracer, etc.) as well as a new data acquisition system in Sainshand (37 $46^{\prime}$ ' North latitude and $37^{\circ} 46^{\prime}$ 'West longitude) - the project site (Fig.1), which is located in southern east part of Mongolia. The data acquisition system (Fig.2) automatically will be switched on at every $10 \mathrm{~min}$ and records the total solar irradiation received on the horizontal and $45^{\circ}$ tilted surfaces, site meteorological data (wind velocity and direction, ambient temperature, humidity) and measures PV module current-voltage (I-V) curves, temperatures. The package of special software for management system is installed in the data acquisition system, which will be supplied by $12 \mathrm{~V}$ at measurement time and data will be loaded into SM4M (storage module of 4Mbyte). The PC208W reads the written data to computer for future processing.

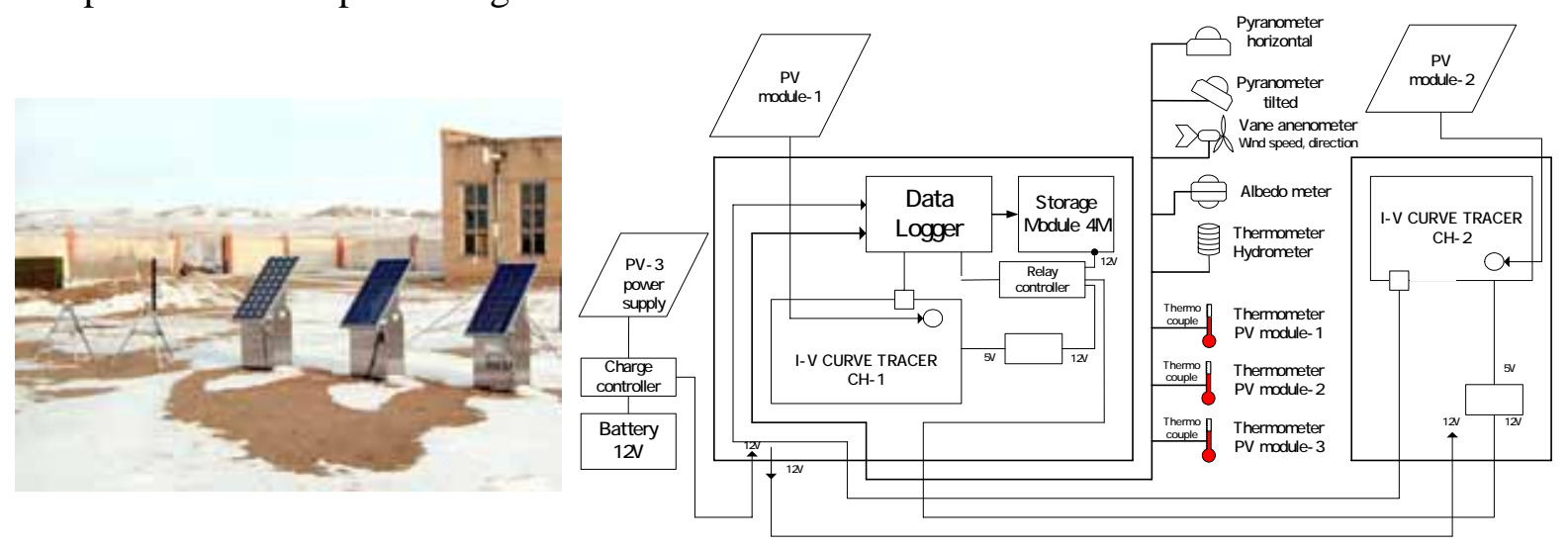

Fig.1: Experimental set-up

Fig.2: Schema of the data acquisition system

\section{ANALYSIS METHOD}

Firstly, initial data obtained from the test site was checked and correctable noise was filtered. The average values of the ambient temperature, module temperature, wind speed/direction, humidity and albedo will be indicated to figure out the real environmental situations of the PV modules.

\section{Solar Energy Resource Indices}

The horizontal and in-plane irradiation $\left[\mathrm{kWh} / \mathrm{m}^{2} /\right.$ day], the time of sunshine duration $T_{\text {Meas.Duration }}\left[\right.$ hour/month] and fraction $F_{S D}$ to possible sunshine duration time were used for the indices of solar energy resource. In order to evaluate the irradiance situation during the measurement period it has been compared monthly irradiance and sunshine duration time to local weather station data. Note: The criteria for determining sunshine duration is as an over $0.2 \mathrm{~kW} / \mathrm{m}^{2}$. 
$F_{S D}=T_{\text {Meas.Duration }} / T_{\text {Possible Duration }}$ (1)

\section{$P V$ Module performance indices}

All system performance data have been evaluated in terms of operational performance and reliability. The evaluation procedures are based on the IEC Standard 61724 [3].

$$
Y_{r}=H_{A} / G_{S} \quad \text { (2) } \quad Y_{A}=E_{A, d} / P_{\max } \quad \text { (3) } \quad K_{\text {module }}=Y_{A} / Y_{r}
$$

The reference yield $\underline{Y}_{r}$ is based on the in-plane irradiation and represents the theoretically available energy per day and $\mathrm{kW}_{\mathrm{p}}$. The array yield $\underline{Y}_{\underline{A}}$ is the daily array energy output per $\mathrm{kW}$ and represents the number of hours per day that the array would need to operate at its rated output power $\mathrm{P}_{\max }$ to contribute the same daily array energy to the system as was monitored. The module performance ratio $K_{\text {module }}$ is the ratio of actual array output energy to the energy theoretically available (i.e. $Y_{A} / Y_{r}$ ). It is independent of location and system size and indicates the overall losses on the array's rated output due to module temperature and incomplete utilization of irradiance .

\section{RESULTS AND DISCUSSION}

\section{Environmental Conditions}

The ambient and module temperature shows in Fig. 2 by the monthly average hour values. The rise of module temperature was 15 to 20 degree $\mathrm{C}$, and module temperature was kept below the standard condition 25 degree $\mathrm{C}$ in April and January.

In the warm season, the albedo is constantly at 0.28 and its increased at winter to 0.4 for a snow cover (See fig.4). The annual albedo during the measuring period was less than $4 \%$ in an average year ${ }^{[6]}$ for few fallen snow. The monthly average humidity was $40 \%$ during the summer season, $60-80 \%$ at the cold season.

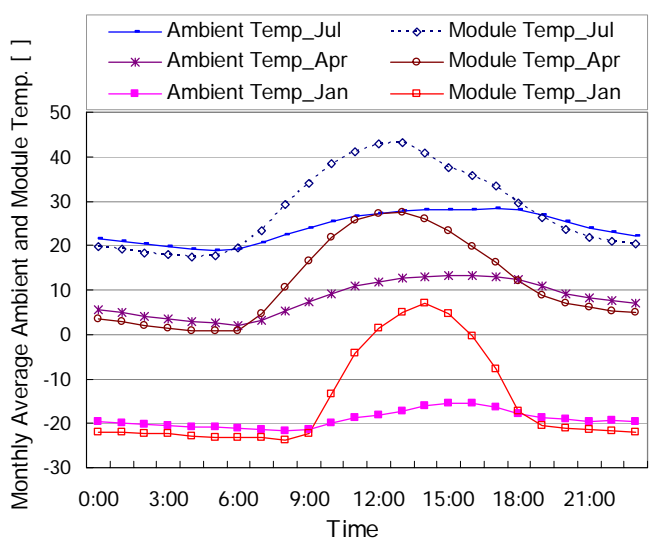

Fig. 3: The Ambient and Module Temperature

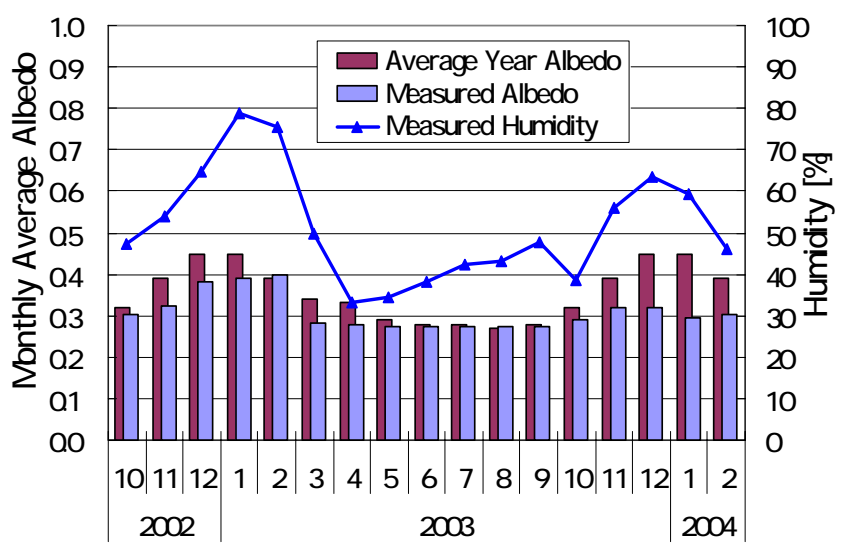

Fig. 4: The Albedo and Humidity variation

\section{Solar Energy Resource}

The fig. 5 shows the monthly variation of sunshine duration time and fraction to ideal duration. The monthly amount of duration time in the winter and summer season are indicated respectively 200 and 300 hour range in a normal year. The fraction of duration was indicated 0.6 in a summer, due to rainy season, in the cold season it's up to 0.8 or more.

The horizontal and in-plane global irradiation shows in the fig. 6 by the monthly average values. 
The annual mean horizontal irradiation indicated $4.66\left[\mathrm{~kW} / \mathrm{m}^{2} /\right.$ day], it is 1.5 fold more than in Sapporo. The tilted irradiation data shows relatively small variation in a year, by reason of the precipitation that concentrated on the summer time.

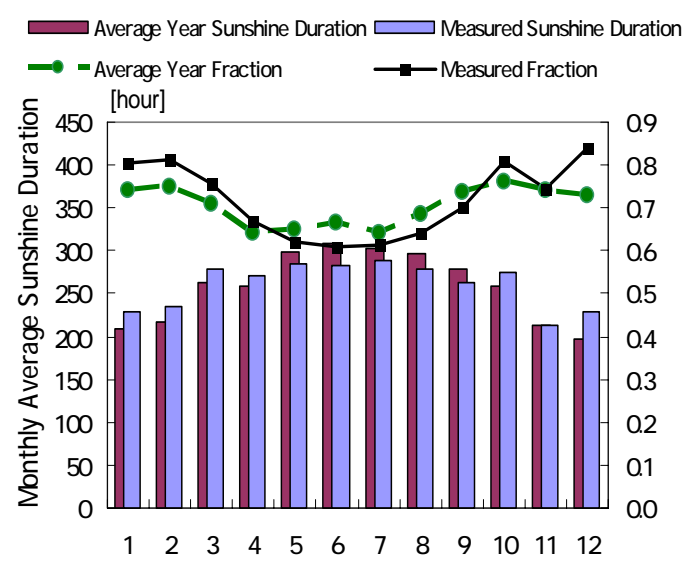

Fig. 5: The Comparison of the Sunshine Duration Time and Fraction to average year

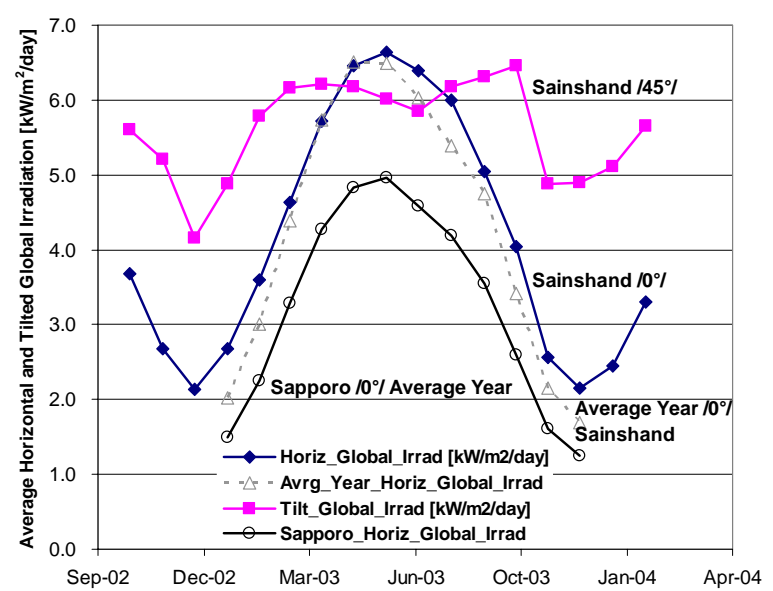

Fig.6: In-plane and Horizontal Global Irradiation with comparison to average year and Sapporo data

\section{PV Module performance}

The figure 7 shows the monthly average output of module 1 and 2 with comparison to the rated output. The annual energy output of module 1 (poly-crystalline, $80 \mathrm{~W}$ ) and 2 (mono-crystalline, $75 \mathrm{~W}$ ) were indicated $384 \mathrm{Wh} /$ day , 338Wh/day.

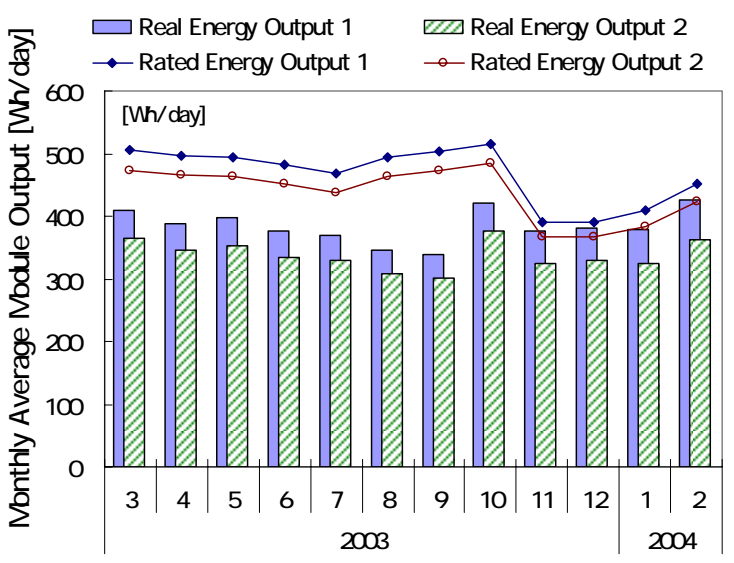

Fig. 7: The Average Outputs of Module 1and 2 with comparison to the rated output.

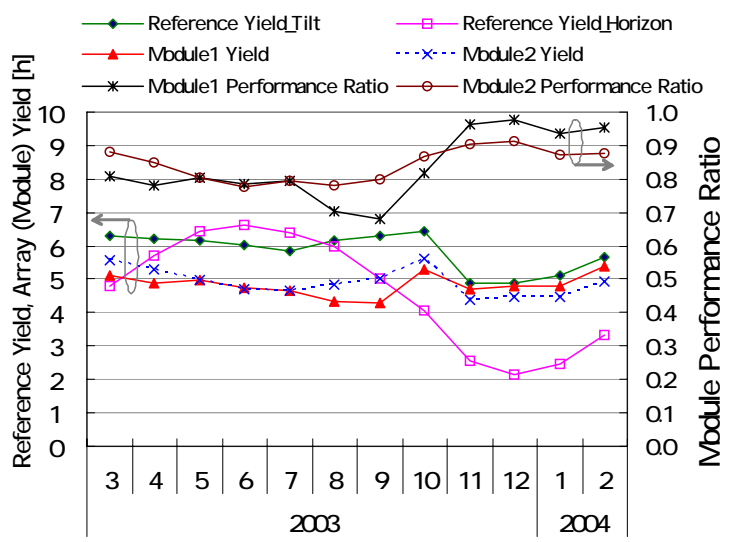

Fig. 8: The Reference Yield, Array Yield and Module performance ratio.

For convince to compare other type modules, the main parameters of PV modules were indicated by reference yield, module yield and performance ratio as fig.8. The losses for incident angle, soilure and temperature rise are included in the difference of rated and measured power outputs. The module performance ratio is indicated very high value 0.9 or more in the winter and 0.7-0.8 in the warm season due to the effect of module temperature. As fig.8, the temperature loss of module 1 are characterize strong as than module 2 . 


\section{CONCLUSIONS}

The accurate determination of the performance of PV modules is crucial for the design of VLS-PV systems and its economic evaluation. In order to develop conceptual design and calculation of the power generation and construction cost for VLS -PV system for the Gobi Desert, it has been developed autonomous PV module performance monitoring devices and data acquisition system. The outdoor performance tests of two types of PV modules have been conducted in Sainshand.

It has been observed that the high output gain due to the operating condition in an extreme low ambient temperature and the module performance ratio indicated very high value 0.9 or more in the winter. The monthly amount variation of in-plane irradiation and module output shows relatively small range in a year, by reason of low ambient temperature and the precipitation that concentrated on the summer time.

For the evaluation of the long term performances of PV module in the severe natural environment, we will continue our field site study.

\section{ACKNOWLEDGEMENT}

The study is carried out by the Japanese-Mongolian Research team within framework of the cooperation between National Institute of Advanced Industrial Science \& Technology, Tokyo University of Agriculture \& Technology and Inter-University Solar Research Net-Center of the National University of Mongolia.

The authors acknowledge the financial support from the National Institute of Advanced Industrial Science and Technology of Japan.

\section{REFERENCES}

[1] Namjil Enebish, M. Battushig, K. Otani, K. Sakuta, A. Adiyabat, K. Kurokawa, Performance monitoring of PV modules for VLS-PV systems in Gobi desert of Mongolia, WCPEC-3, Osaka, May 11-18, 2003, 7P-B3-51

[2] K. Kurokawa, editor: Energy from the Desert, James \& James Ltd., May, 2003, 195 pages

[3] IEC; The International Electrotechnical Commission, "Photovoltaic system performance monitoring Guidelines for measurement, data exchange and analysis", IEC 61724, 1998

[4] U. Jahn, D. Mayer, M. Heidenreich and etc. "International Energy Agency PVPS Task 2: Analysis of the operational performance of the IEA Database PV systems", $16^{\text {th }}$ European Photovoltaic Solar Energy Conference and Exhibition, Glasgow, United Kingdom, May 2000

[5] 新エネルギーロ産業技術総合開発機構委託業務成果報告書「システム評価技術 の研究開発」平成 7 年財団法人日本品質保証機構

[6] D.Davaadorj, P.Gomboluudev, Evaluation report of Renewable Energy Resource in the Dornogobi province, June 1997. 
